\title{
Demographic and Economic Correlates of Mortality Due to Traffic Accidents among Children Aged 1-14 Years in European Countries
}

\author{
*Agnieszka GENOWSKA ${ }^{1}$, Maciej POLAK ${ }^{2}$, Beata GOWORKO-SKŁADANEK ${ }^{3}$, \\ Katarzyna SYGIT ${ }^{4}$, Dorota HUZARSKA ${ }^{5}$, Krystyna SZAFRANIEC ${ }^{2}$
}

1. Department of Public Health, Faculty of Health Sciences, Medical University of Bialystok, Bialystok, Poland

2. Department of Epidemiology and Population Studies, Faculty of Health Sciences, Jagiellonian University Medical College, Krakow, Poland

3. Department of International Relations and Contemporary History, Faculty of History and International Relations, University of Bialystok, Bialystok, Poland

4. Department of Health Promotion, Faculty of Physical Culture and Health Promotion, University of Szczecin, Szczecin, Poland

5. Department of Medical Law and Medical Deontology, Faculty of Health Sciences, Medical University of Bialystok, Bialystok, Poland

*Corresponding Author: Email: agnieszka.genowska@umb.edu.pl

(Received 12 Dec 2018; accepted 19 Feb 2019)

\begin{abstract}
Background: To evaluate the changes of mortality among children aged 1-14 yr due to road traffic injury and related demographic and economic factors in an ecological study undertaken in 33 European countries.

Methods: Information about mortality due to road traffic injury among children aged 1-14 yr in European countries was obtained from the WHO database. Changes in the mortality for the years 2000-2009 were estimated as linear regression. These deaths were correlated with demographic and economic factors.

Results: The greatest burden of child mortality due to road traffic accidents was observed in Baltic States, three times lower mortality levels than that in Northern States. Between 2000 and 2009, there was a significant reduction $(P<0.05)$ in mortality among children aged 1-14 yr in Southern-West countries and Western countries, 1-4 yr in Central and Eastern countries, and 5-14 yr in Northern countries. Mortality due to road traffic injury among boys was strongly associated with the level of urbanization. Both sexes showed strong negative correlations with the economic level and strong positive correlations with income inequality.

Conclusion: Although in European countries the mortality of children due to traffic injury was considerably reduced, efforts should be made to educate and design a safe environment.
\end{abstract}

Keywords: Children; Road traffic injuries; Inequalities in health; Urbanization; Economic status

Introduction

Road traffic injuries (RTIs) involving children are a major public health concern worldwide. In Europe, the most common fatal victims of traffic accidents among pedestrians (48\%), motorists $(32 \%)$, cyclists $(9 \%)$, and motorcyclists $(6 \%)$ were children below $15 \mathrm{yr}$ of age (1). The majority of them were killed in traffic accidents during school holidays, i.e., in the evening from 4 to 8 p.m., on Saturdays and in the July-August holiday months $(2,3)$. The involvement of children

Copyright (C) 2020 Genowska et al. Published by Tehran University of Medical Sciences.

This work is licensed under a Creative Commons Attribution-NonCommercial 4.0 International license

(https://creativecommons.org/licenses/by-nc/4.0/). Non-commercial uses of the work are permitted, provided the original work is properly cited. 
in road traffic was associated with the risk of RTIs because they were unprotected road users such as pedestrians and bicyclists $(4,5)$.

Among children, the most common type of RTI was traumatic brain injury and organ injuries of the abdomen and chest. Traffic accidents can lead to disability, cause life-long physical pain, and mental consequences (1). Estimated calculations indicate that in 2013, RTIs accidents accounted for $3.6 \%$ of all disability-adjusted life years lost in the age group 10-14 (6). In addition to disability, the tragic consequences of RTIs also led to the deaths of children.

In the era of automotive development, RTIs among children were leading causes of death, more often than neoplasms and congenital malformations $(4,7)$. The WHO indicates that the burden of RTIs varies considerably across the world (4). Deaths of children in RTIs accounted for $93 \%$ in low- and middle-income countries, mainly in South-East Asia, Africa, and the Pacific region. In the European Region, mortality due to RTIs was relatively lower, but disparities between high-income countries (5.2/100.000) and lowand middle-income countries $(8.3 / 100.000)$ were observed (4). To our knowledge, no study has been conducted in European countries to assess the inequalities in demographic and economic factors that are associated with RTIs. These factors are beyond the control of children, but their identification can reduce the risk of avoidable deaths in children (8).

We aimed to assess the changes in mortality among children aged 1-14 yr due to RTIs and related demographic and economic factors in an ecological study undertaken in 33 European countries.

\section{Materials and Methods}

The analysis was based on information about the deaths of children aged 1-14 yr, due to RTIs defined by the symbol V01-V99 in the International Statistical Classification of Diseases (ICD10) (9). The present analysis was based on 33 out of 43 countries. Seven countries were excluded owing to the low number of deaths due to RTIs occurring therein (Bosnia and Herzegovina, Iceland, Luxembourg, Malta, Monaco, Montenegro, and San Marino). Another three countries (Cyprus, Russian Federation, and Turkey) were excluded because they classified into the EuroAsian countries.

National registries of death resulting from RTIs took into account different definitions relating to the time elapsed from the occurrence of the event to the death recognized because of accidents. In most European countries, the 30-day criterion applies, whereas in Portugal, the Republic of Moldova and Slovakia there is a different system, which may result in an inconsistency in the estimation of results (10). For this reason, additional analyzes were also performed excluding those countries where no significant differences in the estimated coefficients were observed, so the results are presented for the full model of all analyzed countries.

The European countries were divided into six groups: Baltic (Estonia, Latvia, and Lithuania); Central-Eastern (Belarus, Bulgaria, Czech Republic, Hungary, Poland, Republic of Moldova, Romania, Slovakia, and Ukraine); Northern (Denmark, Finland, Ireland, Norway, Sweden, and United Kingdom); Southern-East (Albania, Croatia, Greece, Macedonia, and Serbia); SouthernWest (Italy, Portugal, Slovenia, and Spain); and Western (Austria, Belgium, France, Germany, Netherlands, and Switzerland).

We analyzed the mortality rate due to RTIs by sex in the age groups 1-4 and 5-14 yr, computed per 100,000 population. In addition, three macrolevel factors were used in the analysis: the degree of urbanization, Gross Domestic Product (GDP) per capita and Gini coefficient. The Demographic variable included urbanization as a percent of the urban population, according to criteria used by each country. The Economic variable that measures national wealth was GDP in US\$ per capita, which represents the sum of gross value added by all resident producers in the economy plus any product taxes and minus any subsidies not included in the value of the product, divided by the mid-year population; and Gini coefficient represented income inequality at the social level, 
the value ranging from 0 (no inequality) to 1 (total inequality). Information on the deaths and demographic and economic factors in the European countries for the years 2000-2009 came from the WHO database (11).

Mortality rates for RTIs in European countries between the years 2000 and 2009 were described by the mean and standard deviation. Comparison of the distribution of mortality rates between boys and girls was performed using the Student's $t$-test for dependent pairs.

Time trend analysis of crude mortality rates due to RTIs, stratified by age categories and groups of countries, was performed using Weighted Least Squares regression models under the assumption of a Poisson error structure. The method allows to correct for random fluctuations in the size of populations and to provide greater stability of mortality rates due to RTIs. Results of the estimated changes were presented as $\beta$ coefficients and their associated $95 \%$ confidence interval. To investigate the relationship between demographic and economic factors, and mortality rates due to RTIs by gender and age category, the Spearman rank correlation was used.

All statistical hypotheses were verified at a significance level of 0.05. Data were analyzed using IBM $^{\circledR}$ SPSS $^{\circledR}$ ver.22 (Chicago, IL, USA).

\section{Results}

In the analyzed European countries for the years 2000-2009, the total number of deaths due to RTIs among boys aged 1-14 yr was 12,649, which accounted for $12.6 \%$ (95\% CI: 12.4-12.8) of all deaths. The number of deaths among girls was significantly lower $(7,790)$ as compared with that of boys, and those occurring due to RTIs in all deaths were 11\% (95\% CI: 10.8-11.2). Mortality due to RTIs among children aged $1-14$ years was unevenly distributed among European countries (Fig. 1). The low mortality burden of RTIs among children aged 1-4 yr was found in Sweden, the United Kingdom, the Netherlands, and Germany. In the older age group of 5-14 yr, the lowest values of mortality ratios were found in Sweden and Norway. High rates of mortality due to RTIs among both boys and girls aged 1-14 yr occurred in Lithuania, Romania and the Republic of Moldova, and among girls aged 1-4 yr in Bulgaria and boys aged 5-14 yr in Latvia and Estonia.

In the analyzed groups of European countries, the lowest burden of child mortality due to RTIs was observed in Northern states among boys and girls aged 1-4 yr $(1.37 / 100,000$ and $1.09 / 100,000$, respectively) and between 5 and 14 years $(1.99 / 100,000$ and $1.07 / 100,000$, respectively). Three-fold higher values of mortality rates were found in Baltic states among boys and girls aged 1-4 yr (5.23/100,000 and 3.02/100,000, respectively) and aged 5-14 yr (6.59/100,000 and $3.64 / 100,000$, respectively). Differences between boys and girls in mortality due to RTIs at $1-14$ ys were statistically significant $(P<0.05)$, except Southern-West and Western countries in the younger age group of $1-4$ years (Table 1$)$.

Table 1: Average mortality rates due to road traffic accidents among children aged 1-14 years by sex, in European countries during the period 2000-2009

\begin{tabular}{|c|c|c|c|c|c|c|c|c|c|c|}
\hline \multirow{3}{*}{ Countries } & \multicolumn{5}{|c|}{ Ages 1-4 (yr) } & \multicolumn{5}{|c|}{ Ages 5-14 (yr) } \\
\hline & \multicolumn{2}{|c|}{ Boys } & \multicolumn{2}{|c|}{ Girls } & \multirow[t]{2}{*}{$\mathbf{P} *$} & \multicolumn{2}{|c|}{ Boys } & \multicolumn{2}{|c|}{ Girls } & \multirow[t]{2}{*}{$\mathbf{P} *$} \\
\hline & $\overline{\mathrm{x}}$ & $S D$ & $\overline{\mathrm{x}}$ & $S D$ & & $\overline{\mathrm{x}}$ & $S D$ & $\overline{\mathrm{x}}$ & $S D$ & \\
\hline Baltic & 5.23 & 2.29 & 3.02 & 1.24 & 0.007 & 6.59 & 1.74 & 3.64 & 1.44 & $<0.001$ \\
\hline Central-Eastern & 3.38 & 0.55 & 2.76 & 0.49 & $<0.001$ & 5.08 & 0.65 & 3.16 & 0.44 & $<0.001$ \\
\hline Northern & 1.37 & 0.30 & 1.09 & 0.28 & 0.040 & 1.99 & 0.45 & 1.07 & 0.24 & $<0.001$ \\
\hline Southern-East & 3.09 & 0.99 & 1.90 & 0.53 & 0.009 & 3.47 & 0.66 & 2.08 & 0.54 & $<0.001$ \\
\hline Southern-West & 1.89 & 0.41 & 1.65 & 0.78 & 0.13 & 2.66 & 0.78 & 1.48 & 0.46 & $<0.001$ \\
\hline Western & 1.67 & 0.47 & 1.37 & 0.42 & 0.01 & 2.06 & 0.64 & 1.40 & 0.46 & 0.001 \\
\hline
\end{tabular}

Abbreviations: $\overline{\mathbf{x}}$, mean; SD, standard deviation.

*Student's $t$-test for dependent pairs 
From 2000 to 2009, significant reductions in mortality due to RTIs among boys and girls aged 1-4 yr due to RTIs occurred in Central-Eastern, Southern-West, and Western states. In this age group in Southern-Eastern states, the reduction in mortality was only among the male gender. Significant reduction in mortality among boys aged 5-14 yr was observed in all the analyzed regions, especially in Baltic countries, whereas among girls in Southern-West, West, and Northern states. Reduction in mortality was more rapid among boys than among girls, especially in the age group 5-14 yr (Table 2). There was a strong relationship between the demographic and eco- nomic characteristics and mortality due to RTIs among children aged 1-4 and 5-14 yr (Table 3). The increase in urbanization was found to be associated with a significant reduction in mortality among boys aged $1-4$ and 5-14 yr. The strongest significant negative relationship was observed between GDP and mortality due to RTIs among children in both age groups and gender. In 2000, the correlation coefficients between GDP and mortality due to RTIs aged 5-14 yr were up to -0.78 and -0.67 , respectively. In children aged 5-14 yr, strong positive correlations were observed with income inequality.

Table 2: Trends in mortality rates due to road traffic accidents among children aged 1-14 years by sex, in European countries (for years 2000-2009)

\begin{tabular}{|c|c|c|c|c|}
\hline \multirow[t]{2}{*}{ Country } & Boys & Girls & Boys & \multirow[t]{2}{*}{ Girls } \\
\hline & \multicolumn{3}{|c|}{$\beta$ - coefficient (95\% CI) } & \\
\hline Baltic & $-0.40(-0.81,0.01)$ & $0.01(-0.32,0.35)$ & $-0.37(-0.75,-0.01)$ & $-0.04(-0.42,0.35)$ \\
\hline Central-Eastern & $-0.16(-0.25,-0.08)$ & $-0.15(-0.19,-0.11)$ & $-0.15(-0.27,-0.06)$ & $-0.08(-0.18,0.02)$ \\
\hline Northern & $-0.05(-0.12,0.03)$ & $-0.05(-0.12,0.02)$ & $-0.14(-0.18,-0.09)$ & $-0.07(-0.12,-0.03)$ \\
\hline Southern-East & $-0.18(-0.36,-0.002)$ & $0.02(-0.10,0.14)$ & $-0.17(-0.31,-0.06)$ & $-0.08(-0.23,0.08)$ \\
\hline Southern-West & $-0.11(-0.16,-0.05)$ & $-0.13(-0.21,-0.06)$ & $-0.26(-0.31,-0.20)$ & $-0.13(-0.18,-0.08)$ \\
\hline Western & $-0.14(-0.20,-0.09)$ & $-0.11(-0.18,-0.04)$ & $-0.20(-0.26,-0.13)$ & $-0.07(-0.10,-0.04)$ \\
\hline
\end{tabular}

Abbreviation: CI, confidence interval.

Table 3: Correlation between demographic and economic characteristics and mortality rates due to road traffic accidents among children aged 1-14 years by sex in European countries

\begin{tabular}{lcccc}
\hline Variable & \multicolumn{2}{c}{ Boys } & Girls & \multicolumn{2}{c}{ Boys } & Girls \\
& \multicolumn{2}{c}{ Ages 1-4(yr) } & Ages 5-14(yr) \\
\hline Urbanization & rho & rho & rho & rho \\
2000 & $-0.63^{* * *}$ & $-0.31^{\dagger}$ & $-0.45^{* *}$ & $-0.34^{\dagger}$ \\
2009 & $-0.61^{* * *}$ & $-0.30^{\dagger}$ & $-0.47^{* *}$ & $-0.33^{\dagger}$ \\
GDP & & & & \\
2000 & $-0.65^{* * *}$ & $-0.46^{* *}$ & $-0.78^{* * *}$ & $-0.67^{* * *}$ \\
2009 & $-0.61^{* * *}$ & $-0.42^{*}$ & $-0.73^{* * *}$ & $-0.62^{* * *}$ \\
Income inequality & & & & \\
2000 & $0.46^{*}$ & $0.43^{\dagger}$ & $0.60^{* *}$ & $0.59^{* *}$ \\
2009 & $0.33^{\dagger}$ & $0.3 \dagger^{\dagger}$ & $0.45^{*}$ & $0.37^{*}$ \\
\hline
\end{tabular}

Abbreviation: GDP, Gross Domestic Product, rho- Spearman rank correlation coefficient

tP $<0.1,{ }^{*} P<0.05,{ }^{* *} P<0.01,{ }^{* * *} P<0.001$ 


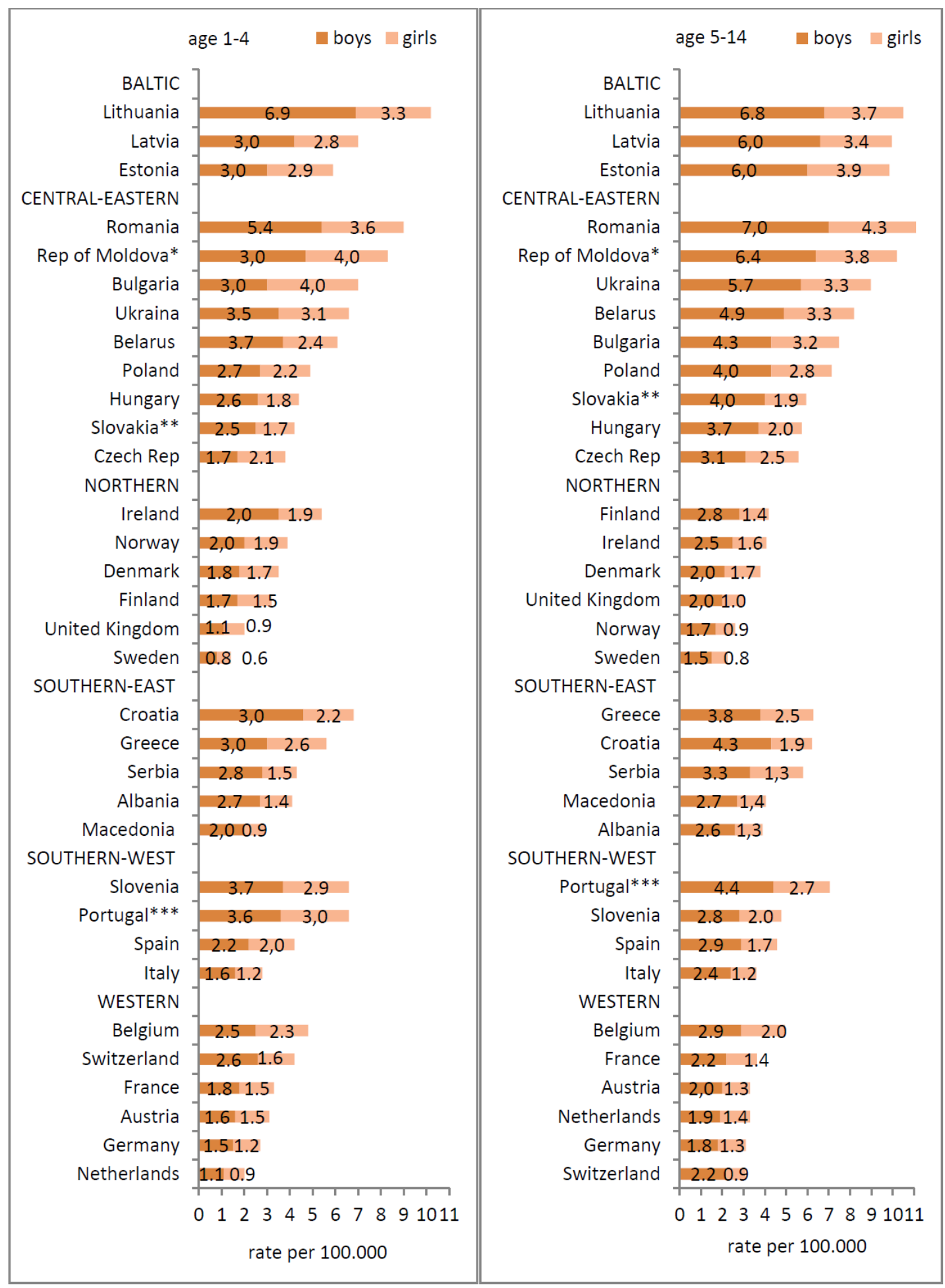

Fig. 1: Mortality rates for road traffic accidents among children aged 1-14 years by sex, in European countries during 2000-2009

Defined period of recording deaths because of traffic accidents: * within 1 year; ** within 24 hrs; *** at the scene; other countries: within 30 days 


\section{Discussion}

In European countries, there are significant disparities in mortality due to RTIs among children aged 1-14 years. The highest levels of mortality occurred in the Baltic States, whereas 3 times lower rates were observed in Northern states. In the years 2000-2009, RTIs among children aged 1-14 years significantly decreased in SouthernWest and Western countries, 1-4 yr in CentralEastern and 5-14 yr in Northern countries. Mortality due to RTIs among boys were strongly associated with the level of urbanization. Both sexes showed strong negative correlations with economic level and strong positive correlations with income inequality. Similar results that showed the decrease of mortality due to RTIs was confirmed by studies performed in the United States, Australia, and Iran $(12-14,16)$. There are also studies suggesting stagnant or increasing mortality trends due to RTIs in most developing countries (15). Observations regarding lower exposure to mortality due to RTIs in children in urban areas were confirmed by other authors $(13,16-18)$. The Economic disadvantage that increases a child's risk of mortality due to RTIs were in line with other papers $(19,20)$.

In European countries, there were significant inequalities in the health of children aged 1-14 yr with differences in mortality due to RTIs. Mortality in Northern Europe (Denmark, Finland, Ireland, Norway, Sweden, and United Kingdom), which was 3 times lower than that in the Baltic states (Estonia, Lithuania, and Latvia) and some Central-Eastern countries (Bulgaria, Republic of Moldova, and Romania) was strongly associated with the level of economic development and income inequality. Similar results have been reported in other studies $(20,21-23)$, but it should be noted that economic differences shape different opportunities for the implementation of road safety strategies and programs, the development of road infrastructure, and the availability of medical care. In addition to economic determinants, the possible explanation for inequalities among mortality of children due to RTIs were the differences resulting from ineffective en- forcement, including the control of risk factors such as speed, alcohol consumption and use of safety devices: child safety seats, safety helmets, safety belts $(10,22,24)$. Unfortunately, half of the countries in the European region did not have comprehensive provisions on the control of risk factors (25). Only two countries (Czech Republic and Sweden) have adopted the infrastructure and had the capacity to take related actions to support child safety, four countries (Belgium, Germany, Hungary, and Sweden) reported that injury prevention has been identified as a national priority by the government. Differences in mortality of children among European countries can be interpreted as a measure of prevention potential and an indication for action in countries with worse outcomes. Interventions to modify dangerous environments through a combination of engineering, education and enforcement should be targeted specifically at children from low-income families, at risk of multiple-generation poverty, and adapted to the rural environment (26).

Mortality due to RTIs among children younger than $15 \mathrm{yr}$ in the years 2000-2009 decreased in Southern-West and Western countries, and this result was consistent with that of other authors $(12-14,16)$. In many countries, this trend has been observed since the middle of the last century, which may be due to the introduction of road safety measures $(27,28)$. The results of this study indicate that in Northern countries, among children aged 1-4 yr, there was no change in mortality, but the values in this age group were relatively low, which may explain the lack of significant dependence. In contrast, in the Baltic and Southern-East countries, insignificant results for the trend of mortality can be explained by poorer road safety achievements (26). In general, highincome European countries have adopted many preventive measures to avoid RTIs among children. Consequently, these countries have examples of good practices that have the potential to reduce child mortality. In Sweden, road safety reform strategies are based on the Vision Zero approach, where life and health cannot be compromised for any other benefit to society. 
Vision Zero is a program of research and implementation of solutions aimed at successively reducing RTIs aimed at the non-acceptance of road deaths (29). This concept adopts a new philosophy, according to which the child should not adapt to road conditions, but the road conditions should be adapted to the limitations of the child (30). This approach has contributed to the reduction of children's mortality due to RTIs by improving traffic planning, separating bicycle paths from pedestrian pathways, the emergence of safer vehicles, and the right equipment in cars to increase the safety of children who are traveling. Moreover, the impact on the reduction of road traffic victims was also a consequence of the decrease in the number of free-traveling children and cyclists (31). This example shows that the most important element of road safety for children is to create a safe environment for them. To mitigate RTIs, Sweden focuses on designing road infrastructure and reducing speed.

In European countries, mortality due to RTIs of children aged 1-14 yr was associated with the degree of urbanization and the level of economic development. The risk of mortality due to RTIs among children is often the result of multiple simultaneous influences, including environmental, socioeconomic, behavioral, regional, and demographic characteristics (32). The importance of explaining the risk of mortality caused by RTIs may be inhabited, constituting a heterogeneous category of the rural-urban continuum (33-35). The urban living environment was significantly less exposed to RTIs, which was conditioned by the economic resources that enable better road infrastructure $(17,36)$. In addition, urban traffic safety was controlled more frequently in urban areas, and law enforcement was more effectively enforced $(17,37)$. However, in rural areas, drivers were more likely to drive under the influence of alcohol and at higher speeds, so children who were biking or walking were more likely to be exposed to RTIs $(17,21)$. In rural areas, injury severity was much higher compared with that in urban areas, which was magnified due to delays in medical aid arriving at the scene and transporting the injured to the hospital (38). Differences in income levels between rural and urban areas may entail the purchase of safety equipment or safer cars but also differences in educational levels that determine the use of seat belts and children's safety seats (19, 36). An important factor in protecting against RTIs was the education of children; however, deficits in this area reduce the equal opportunities for rural and urban students in accessing resources that can protect against RTIs.

In most European countries, sex was associated with the occurrence of inequalities in health, manifesting with significantly higher mortality due to RTIs among boys. This phenomenon can be explained by the biological and sociocultural differences that affect the health behaviors and attitudes toward health (36). Boys are more impulsive and willing to engage in risky behaviors, which is also due to the tendency to react to peer pressure. No experience, bravado on the road, especially in bikers less than 14 years contribute to the high risk of mortality due to RTIs. Among girls, greater involvement in housework and lower physical activity may act as a protective factor $(4,39)$. There is therefore a need for knowledge-aimed actions related to risk factors of RTIs at all stages of education and appropriate media selection (16).

Ensuring children's road safety, in addition to their health benefits, can bring tangible economic benefits in the form of reduced health care and social services and greater productivity in the future. It is estimated that counteracting child RTIs is economically viable as the rate of return of 1 dollar invested is $\$ 45$ (40). Designing a safe environment and promoting road safety can contribute not only to the reduction of mortality but also to the improvement of public health and the quality of life. These actions should be given high priority because of the unfavorable demographic trends facing every child who becomes a valuable asset to society as a whole.

The study's limitation was the lack of detailed information in the WHO databases on RTIs risks (road conditions, driving speed, type of collision, child safety, alcohol consumption by drivers). These deficiencies made it impossible to identify the more relevant causes of mortality due to RTIs in children aged 1-14 years. On the other hand, 
our paper shows the mortality due to RTIs in 33 European countries among children aged 1-14 yr by sex in the 10-year follow-up period. Research on differences in mortality due to RTIs is necessary to assess the scale of this problem and to monitor the implementation of national road safety strategies (26). Another advantage of this study was the use of comparable mortality information due to RTIs at national population levels, resulting in high statistical power and estimation of mortality relationships with demographic and economic characteristics. The use of quantitative measurement through a correlation-based ecological study can provide an insight when individuallevel information is unavailable (37). The results may point to further investigations into the causes of childhood mortality due to RTIs, particularly about rural-urban criteria.

\section{Conclusion}

Although in European countries, the mortality of children aged 1-14 yr due to RTIs has significantly decreased, this issue remains a challenge for public health institutions. Territorial inequalities between the Baltic and Northern countries in the mortality of children due to RTIs indicate the need to finance the design of a safe environment with the use of road engineering, as well as education and effective enforcement, especially in less-urbanized areas.

\section{Ethical considerations}

Ethical issues (Including plagiarism, informed consent, misconduct, data fabrication and/or falsification, double publication and/or submission, redundancy, etc.) have been completely observed by the authors. As no primary data collection was undertaken, no additional formal ethical assessment and informed consent were required.

\section{Acknowledgements}

This project was supported by the Medical University of Bialystok, grant N/ST/ZB/17/002/3303

Available at: http://ijph.tums.ac.ir

\section{Conflict of interest}

None declared.

\section{References}

1. Sethi D, Towner E, Vincenten J et al (2008). European report on child injury prevention. World Health Organization. Available from: https://apps.who.int/iris/bitstream/handle/ 10665/326500/9789289042956eng.pdf?sequence $=1$ \&isAllowed $=\mathrm{y}$

2. European Commission. Traffic Safety Basic Facts - Children (2016). Available from:http://ec.europa.eu/transport/road_saf ety/sites/roadsafety/files/pdf/statistics/daco ta/bfs2016_children.pdf

3. Domżał-Drzewicka R, Saracen A, Rząca $\mathrm{M}$ et al (2016). Retrospective study of injury rates among children and adults in the Lublin Region of Poland. Ann Agric Environ Med, 23(2): 297-303.

4. Peden M, Oyegbite K, Ozanne-Smith $\mathrm{J}$ et al (2008). World report on child injury prevention. Geneva: World Health Organization. Available from: https://apps.who.int/iris/bitstream/handle/ 10665/43851/9789241563574_eng.pdf?sequ ence $=1$

5. Dissanayake D, Aryaija J, Wedagama D (2009). Modelling the effects of land use and temporal factors on child pedestrian casualties. Accid Anal Prev, 41(5): 1016-1024.

6. Mokdad A, Forouzanfar M, Daoud F et al (2016). Global burden of diseases, injuries, and risk factors for young people's health during 1990-2013: a systematic analysis for the Global Burden of Disease Study 2013. Lancet, 387(10036): 2383-2401.

7. Rahbar M, Ahmadi M, Lornejad H et al (2013). Mortality causes in children 1-59 months in Iran. Iran J Public Health, 42(Supple1): 93-97.

8. Sidebotham P, Fraser J, Covington T et al (2014). Understanding why children die in highincome countries. Lancet, 384(9946): 915-927.

9. World Health Organization. International Statistical Classification of Diseases and Related Health Problems 10th Revision (ICD-10). Version for 2016. Available from: 
http://apps.who.int/classifications/icd10/br owse/2016/en

10. World Health Organization (2009). European status report on road safety. Towards safer roads and healthier transport choices. World Health Organization. Available from: http://www.euro.who.int/_data/assets/pdf _file/0015/43314/E92789.pdf

11. World Health Organization (2017). European Health for All family of databases. Available from: http://www.euro.who.int/en/dataand-evidence/databases/european-healthfor-all-family-of-databases-hfa-db

12. Rockett I, Regier M, Kapusta N et al (2012). Leading causes of unintentional and intentional injury mortality: United States, 20002009. Am J Public Health, 102(11): e84-92.

13. Chang S, Symons R, Ozanne-Smith J (2018). Child road traffic injury mortality in Victoria, Australia (0-14 years), the need for targeted action. Injury, 49(3): 604-612.

14. Hasanzadeh J, Moradinazar M, Najafi $F$ et al (2014). Trends of mortality of road traffic accedents in Fars Province, Southern Iran, 2004-2010. Iran J Public Health, 43(9): 12591265.

15. Kyu H, Pinho C, Wagner J et al (2016). Global and national burden of disease and injuries among children and adolescents between 1990-2013: findings from the Global Burden of Disease 2013 Study. JAMA Pediatr, 170(3): 267-287.

16. Kim K, Ozegovic D, Voaklander D (2012). Differences in incidence of injury between rural and urban children in Canada and the USA: a systematic review. Inj Prev, 18(4): 264-271.

17. Kmet L, Macarthur C (2006). Urban-rural differences in motor vehicle crash fatality and hospitalization rates among children and youth. Accid Anal Prev, 38(1): 122-127.

18. Cheng P, Yin P, Ning P et al (2017). Trends in traumatic brain injury mortality in China, 2006-2013: a population-based longitudinal study. PLoS Med, 14(7): e1002332.

19. Laflamme L, Hasselberg M, Burrows S (2010). 20 Years of research on socioeconomic inequality and children`s-unintentional injuries understanding the cause-specific evidence at hand. Int J Pediatr, 2010:819687.

20. D'Souza A, Blakely T, Woodward A (2008). The effect of eradicating poverty on childhood unintentional injury mortality in New Zealand: a cohort study with counterfactual modelling. J Epidemiol Community Health, 62(10): 899-904.

21. Hasselberg M, Laflamme L (2004). Children at risk in traffic: improvement potentials in the Swedish context. Acta Paediatr, 93: 113-119.

22. International Road Traffic and Accident Database (2015). Road safety annual report 2015. Organization for Economic Co-operation and Development; International Transport Forum.

23. Patton G, Coffey C, Sawyer S et al (2009). Global patterns of mortality in young people: a systematic analysis of population health data. Lancet, 374(9693): 881-892.

24. Hardelid P, Davey J, Dattani N et al (2013). Child deaths due to injury in the four UK countries: a time trends study from 1980 to 2010. PLoS One, 8(7): e68323.

25. Mitis F, Sethi D (2013). European facts and global status report on road safety 2013. World Health Organization.

26. MacKay M, Vincenten I (2012). Child Safety Report Card 2012: Europe Summary for 31 Countries. EuroSafe.

27. Viner R, Coffey C, Mathers C et al (2011). 50year mortality trends in children and young people: a study of 50 low-income, middleincome, and high-income countries. Lancet, 377(9772): 1162-74.

28. Mytton J, Towner E, Powell J et al (2012). Taking the long view: a systematic review reporting long-term perspectives on child unintentional injury. Inj Prev, 18(5): 334-342.

29. Vision Zero. Traffic safety by Sweden (2017). https://www.itfoecd.org/sites/default/files/sweden-roadsafety.pdf

30. European Transport Safety Council (2009). Reducing child deaths on European Roads. Brussels: European Transport Safety Council.

31. Myndigheten för Samhällsskydd och Beredskap (2011). Barns och ungas säkerhet. MSB. Available from: https://www.msb.se/RibData/Filer/pdf/26 005.pdf (Swedish).

32. Fraga A, Fraga G, Stanley C et al (2010). Children at danger: injury fatalities among children in San Diego Country. Eur J Epidemiol, 25(3): 211-217.

Available at: http://ijph.tums.ac.ir 
33. Li M, Doong J, Chang K et al (2008). Differences in urban and rural accident characteristics and medical service utilization for traffic fatalities in less-motorized societies. I Safety Res, 39(6): 623-630.

34. Singh G, Azuine R, Siahpush M et al (2013). Allcause and cause-specific mortality among US youth: socioeconomic and rural-urban disparities and international patterns. J Urban Health, 90(3): 388-405.

35. Bakke H, Hansen I, Bendixen A et al (2013). Fatal injury as a function of rurality-a tale of two Norwegian counties. Scand J Trauma Resusc Emeng Med, 21: 14.

36. Jiang $X$, Zhang $Y$, Wang $Y$ et al (2010). An analysis of 6215 hospitalized unintentional injuries among children aged 0-14 in northwest China. Accid Anal Prev, 42(1): 320-326.

37. Macpherson A, To T, Parkin P (2004). Urban/rural variation in children's bicycle- related injuries. Accid Anal Prev, 36(4): 649654.

38. McGuffie A, Graham C, Beard D et al (2005). Scottish urban versus rural trauma outcome study. J Trauma, 59: 632-638.

39. European Commission (2012). Children in road traffic. Deliverable $4.8 \mathrm{c}$ of the EC FP7 project

DaCoTA. https://ec.europa.eu/transport/road_safety/ sites/roadsafety/files/specialist/erso/pdf/saf ety_issues/age_group/01child_traffic_safety_en.pdf

40. Children Safety Network (2014). Injury prevention. What works? A summary of costoutcome analysis for injury prevention programs (2014 Update). Childrens Safety Network; Pacific Institute for Research Evaluation. 